\title{
Probity In Procurement In The Private Sector In Zimbabwe. A Case Study Of Selected Businesses In Harare.
}

\author{
Mr. D. Ndudzo \\ Registrar, Zimbabwe Open University, Zimbabwe
}

\begin{abstract}
The study focused on examining probity in procurement in the Private Sector, that is, it sought to establish whether processes followed in the Procurement departments were in line the laid down procedures, laws and regulations that governs procurement in the Private sector. The descriptive research design was adopted in the study because the researcher sought the opinions and views of the procurement personnel in the Private sector. Questionnaires were designed and administered to a sample of thirty companies in Harare which were randomly selected. Results of the research showed that probity principles were observed when conducting the procurement function to some extend but the procurement function was more prone to the risks of fraud, misconduct and corruption. The researcher recommended that procurement staff must be educated on the strategic significance of purchasing and supply management and the potential it holds for gaining a competitive advantage in an increasingly difficult and competitive business environment. This will assist the procurement staff to develop a broader perspective and understanding of the contributions of conducting procurement with probity in mind.
\end{abstract}

\section{Introduction}

The Private sector is that part of the economy which is run by private individuals or groups as means of enterprise for profit and is not controlled by the state. It is legally regulated by the state and is required to comply with the laws of the country. The profit making initiative of these businesses can be best achieved when procurement is done with probity in mind. Best probity principles such as transparency, fairness, integrity competition confidentiality and security, loyalty and respect for rules and regulations and due diligence must be consistently observed when undertaking the procurement function.

Gilbert Muponda in his article "Privatization can aid Zimbabwe's economic recovery 2009" advocated that Sub- Saharan African states need expanded and more dynamic private sectors, more efficient and effective infrastructure/ utility provision and increased investment from both domestic and foreign sources. This entails the importance of having a vibrant Private sector in the country.

Probity has been defined by Miriam Webber as the evidence of ethical behavior in a particular process, adherence to the highest principles and ideals or can be defined as complete and confirmed integrity, uprightness and honesty in a particular process. It can be noted from the above definitions that probity evolves around adherence to highest standards of ethics. J.A. Baden horst defined ethics as the basic principles regarding the right behavior in personal or professional conduct. This however implies that procurement staff must be highly principled and should always adhere to the highest ethical standards and guidelines. An organization's reputation and image can be largely affected by its approach to procurement and also securing value for money and confidence in the outcome is dependant upon the proper conduct of the procurement.

The need for assessing probity in procurement originates from the need to provide assurance to the public that the organizations adhere to the applicable laws and regulations that governs the procurement function. This study will be used by the organizations in the Private sector as means of contributing to an open and accountable procurement practice demonstrating the transparency of operations and ensuring that value money is obtained. The value for money is best achieved by encouraging competition for business among all potential suppliers and making decisions in an accountable and transparent manner.

Maintaining probity involves more than just simply avoiding corrupt or dishonest conduct. It involves applying values such as impartiality, accountability and transparency. In order to achieve an ethical and transparent approach, procurement rules must be clear, open, well understood and applied equally to all parties to the process. (Steve Moro, 2011).

The major objective of this study is to examine and evaluate if information and processes followed are consistent with appropriate regulations, guidelines and best practice principles of openness and transparency. It also aims to provide evidence of the current practice of probity by the firms in the Private sector.

\section{Statement Of The Problem}

The Procurement personnel must carry out their mandate of buying and hiring of goods and services for the organization through legal and ethical means and in an economical manner in order to contribute to the 
profit making objective of the organization. Economical buying entails getting the best quality goods and services at the lowest possible price thus getting value for money. All this can be best achieved when procurement is conducted with probity in mind. No study has ever been carried out to examine if probity principles are being observed when undertaking the procurement function in the private sector.

\section{Aim Of The Study}

The study aims to examine whether probity principles are being followed by Procurement personnel when executing their procurement function. It is hoped that results of the study will help the Private sector organizations develop strategies to improve the overall efficiency of the Procurement unit.

\section{Objectives Of The Study}

The researcher aims to achieve the following objectives;

1. To assess the integrity of procurement personnel.

2. To examine and evaluate if processes followed are consistent with the established laws and best probity principles.

3. To assess the views of the procurement staff regarding the observing of probity in Procurement.

4. To examine if observing probity in procurement improves efficiency and effectiveness in procurement.

5. To ensure the procurement activity provides the best outcome.

6. To avoid the potential for misconduct, fraud and corruption.

\section{Research Questions}

1. Is there any evidence which demonstrates the integrity of the procurement personnel in the private sector?

2. Are the processes followed by the procurement staff consistent with the established laws and regulations that governs the country's procurement process?

3. What are the views of procurement staff regarding probity in Procurement the private sector?

4. Does observing probity in procurement improve efficiency and effectiveness in the private sector?

5. Is the procurement function providing the best outcome for the private sector?

6 . Is there any potential for misconduct, fraud and misconduct?

\section{Justification Of The Study}

For overall effectiveness and efficiency of the Private sector organizations, it is imperative that procurement be done with probity in mind. Efficiency in procurement implies that goods and services are acquired on the best possible terms, are appropriate to requirement and that the chosen provider has competence to perform the required contract (Nyasha Chizu 2013) This study will examine if probity principles are being observed when conducting the procurement function. It is highly hoped that results of this study will assist in evaluating the performance of the procurement units in line with the set laws and regulations.

Corruption cases have been reported more often worldwide in both the public and private sector. With this in mind there is a strong need to provide assurance to all stakeholders that Procurement is being done according to the established rules and regulations. Such assurance can be given to stakeholders by proving that probity is being observed when undertaking the Procurement function. This study will serve such purpose.

There is a high risk in Procurement therefore risk management is highly recommended. The Procurement function is responsible for spending the organization's funds through acquisition of goods and services required by the organization hence there is a risk of being duped by suppliers if proper procedures and regulations are not followed. This implies that there is need to conduct probity audits to make sure that proper procedures are strictly adhered to.

\section{Literature Review}

Gray and Jenkins (1985) defined probity audits as an expression of interest to ascertain whether procedures followed are consistent with appropriate regulations, guidelines and best practice principles of openness and transparency.

Guthrie J. (2012) advocates that maintaining probity in procurement involves more than simply avoiding corrupt or dishonest conduct, it means ethical behavior that upholds public values and ensures impartiality, accountability and transparency. There are several benefits that accrue from observing probity inn procurement which includes enhancing confidence in stakeholders and minimizing the cost of managing risks.

The Western Australia's department of Health conducted a study on probity in Health infrastructure in 2006 and alluded that a tendering process which conforms to the expected standards of probity is one in which clear procedures, consistent with the government and the legitimate interests of bidders are established, understood and observed from the outset. 
However studies conducted on probity in procurement were mostly done in the European countries hence the geographical distance between them and Zimbabwe has to be covered. The differentiation in the economies of the European and African countries has prompted the researcher to carry out the study on probity in procurement in Zimbabwe's private sector business.

Steve Moro (2011), advocated that maintaining probity involves more than just simply avoiding corrupt or dishonest conduct. It involves applying values such as impartiality, accountability and transparency. In order to achieve an ethical and transparent approach procurement rules must be clear, open, well understood and applied equally to all parties to the process.

\section{Methodology}

The study adopted a qualitative research paradigm. McMillan and Schumacher (1993) defined qualitative research as an inductive process of organizing data into categories. Questionnaires were used as the instrument for data collection because questionnaires are not only economic but are also easier to administer (Hopkins 1989). The questionnaires were administered to a sample of thirty (30) business organizations in the private sector in Harare. The companies were selected using the purposive sampling technique and the convenience factor was also taken into consideration. The questions were designed based on the best probity principles of transparency, Integrity, security and confidentiality, Fairness, Competition and respect for rules and regulations.

The researcher employed the descriptive survey in the research because the study required opinions, views and perceptions of the procurement staff in different companies.

\section{Discussion Of Findings}

\subsection{Gender}

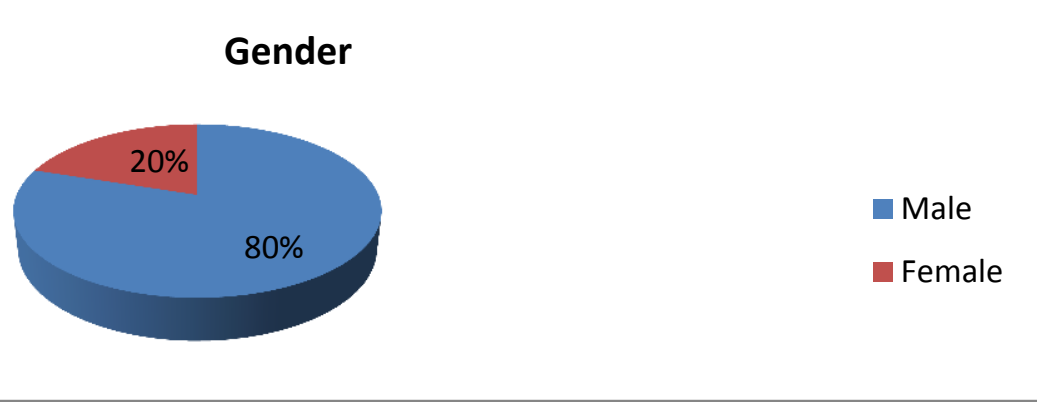

Figure 1: Gender

Results of the survey showed that $80 \%$ of the respondents are male employees and $20 \%$ were female. This goes to show that there is male dominance in the procurement field in the Private sectors and there is still lack of gender balance.

\subsection{Fairness}

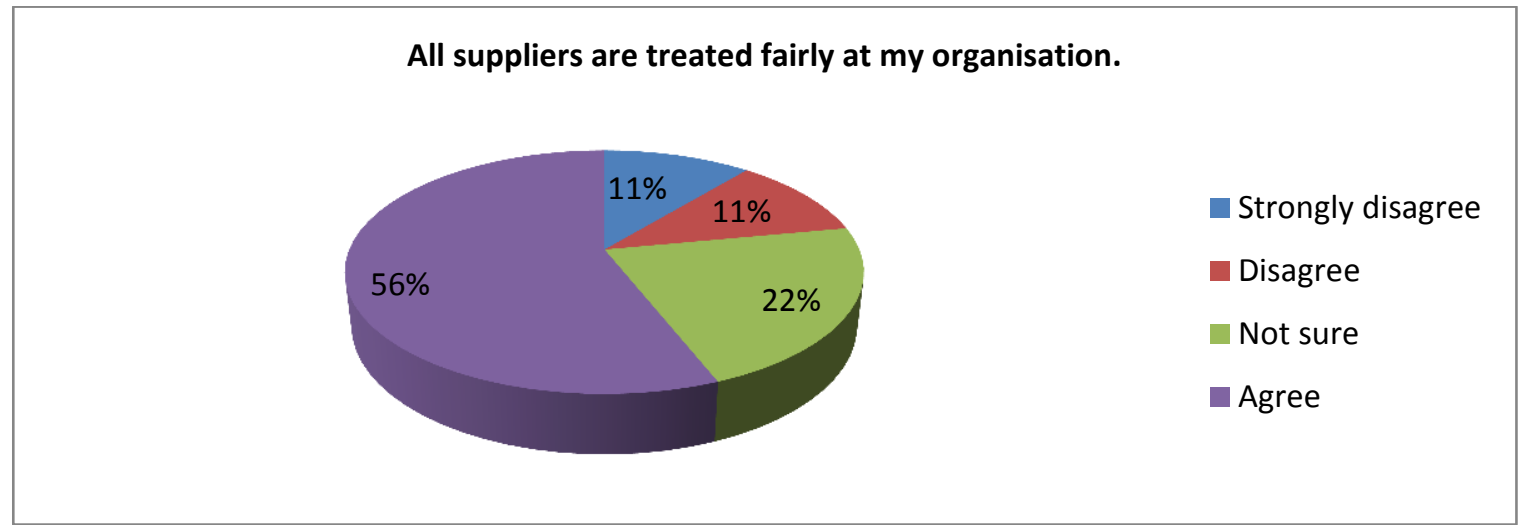

Figure 2: Suppliers are treated fairly at my organization.

Respondents were asked their opinion on whether suppliers were treated fairly at their organizations and $56 \%$ positively agreed, $22 \%$ were not sure while $22 \%$ were in disagreement. Generally suppliers are not being fairly treated as expected in business ethics since they are the major drivers of the organization by availing goods and services required by the organization. This largely affects the profit making initiative of the 
organizations because unfair treatment drives away suppliers due to the unfavorable business environment created by the organization.

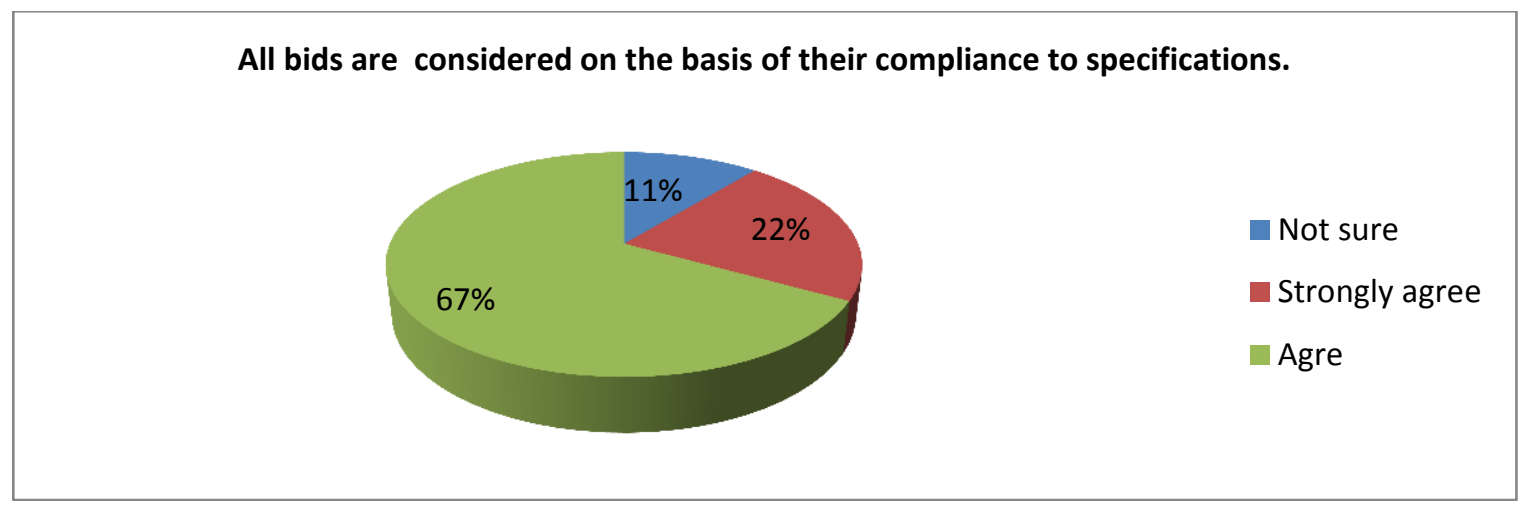

Figure 3: All bids are considered on the basis of their compliance to specifications

$89 \%$ of the procurement staff in the Private sector agreed to the fact that bids were considered on the basis of their compliance to specifications. Only $22 \%$ were not sure about the issue. The results shows that there is efficiency in procurement and also that there is high level of adherence to specifications when considering bids thereby giving a high possibility of receiving the right goods and services as requested by the user departments.

\section{Suppliers can challenge the selection process whenever they feel that they are unfairly treated.}

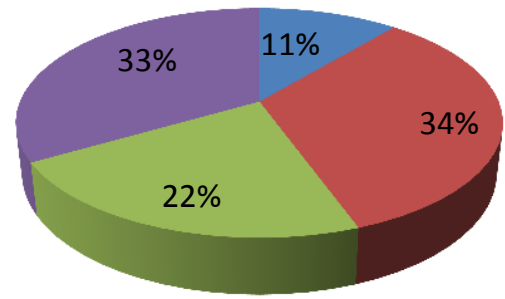

- Strongly disagree

Disagree

Strongly agree

Agree

Figure 4: Suppliers can challenge the selection process when they feel that they were unfairly treated.

It has emerged that $45 \%$ of organizations in the Private sector does not allow suppliers to challenge their selection process when they feel unfairly treated as exhibited by results. 55\% of the respondents positively agreed that suppliers can challenge their selection process if they feel unfairly treated. Though majority of the respondents have agreed to the challenge, quite a bigger percentage of the companies are yet to accept challenge. This however, hinders growth and generation of new ideas that may be brought through analyzing the procurement process together with the suppliers. Allowing suppliers to challenge the organization's procurement process makes suppliers feel guaranteed of the outcome of the organization's procurement process. 


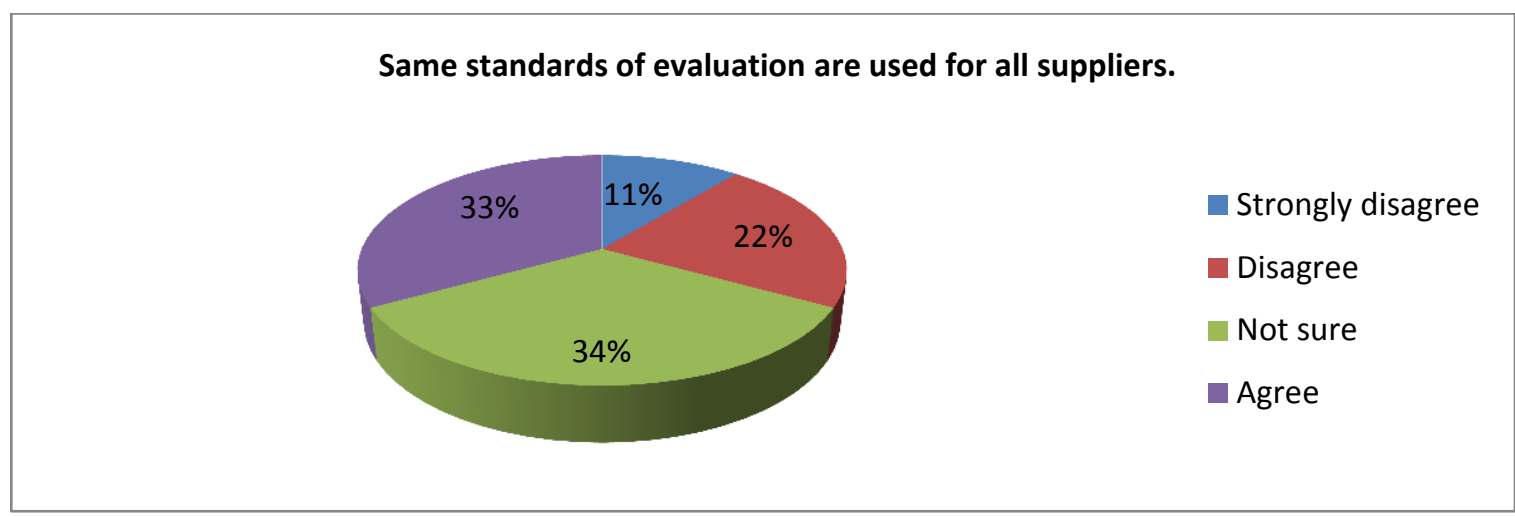

Figure 5: Same standards of evaluation are used on all suppliers.

$67 \%$ of the respondents were either disagreeing or not sure whether same standards of evaluation were used for all suppliers. Only 33\% of the respondents were in agreement. These results prove that there is a risk of favoring some suppliers over others by relaxing the evaluation standards and criterion for some suppliers over others.

\subsection{Integrity}

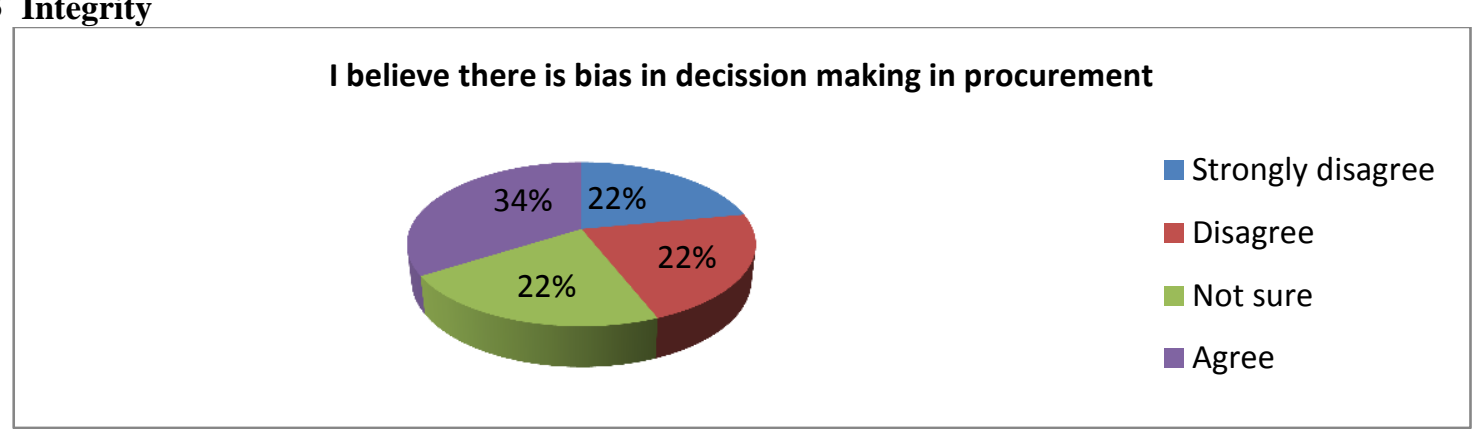

Figure 6: I believe there is bias in decision making in procurement.

When asked about the existence of bias in decision making in Procurement, $44 \%$ disagreed, $22 \%$ were not sure and 34\% agreed that there was bias in decision making in Procurement. Organization's image can easily be affected by poor decision making and at times there is need for brainstorming of ideas among staff members in the unit when an important decision is to be made in order to come up with a wider range of options to decide on.

\section{Suppliers are told and know how they will be evaluated}

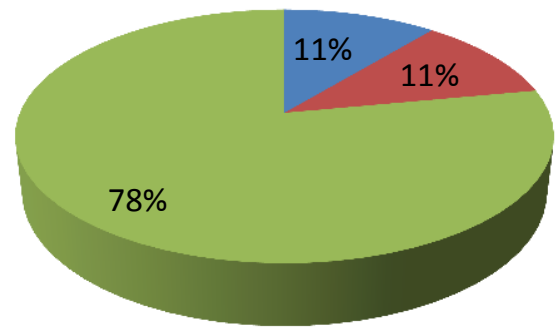

Strongly disagree

Strongly agree

Agree

Figure 7: Suppliers are told, and know how they will be evaluated.

Findings seem to support that suppliers are being told and know how they will be evaluated by the procuring organizations. 89\% agreed that suppliers were told and know how they will be evaluated whilst 11 strongly disagreed with that idea. These results demonstrate the integrity of the process and the personnel in executing their mandate. Such information to suppliers helps them to clearly understand the requirements and expectations of your organization from them. 
Figure 8: Procurement personnel at my organization are honest at all times.

\begin{tabular}{|l|l|}
\hline Procurement personnel at my organisation are honest at all times. & Strongly disagree \\
$22 \% \quad 11 \%$ & Disagree \\
\hline $11 \%$ & Not sure \\
& Strongly agree \\
& Agree
\end{tabular}

The procurement staff showed some mixed reactions about the issue of them being honest at all times. $11 \%$ strongly agreed, $22 \%$ agreed, $22 \%$ were not sure, $34 \%$ disagreed and $11 \%$ strongly disagreed. Results show a relatively low level of honesty of the procurement staff. Ethics training is often required for the procurement staff to constantly remind them on the need to be honesty when conducting the procurement function.

\subsection{Transparency}

Suppliers have access to information pertaining my organisation's procurement process.

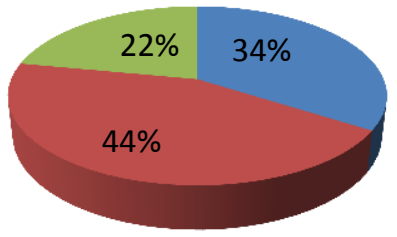

Strongly disagree

Not sure

Agree

Figure 9: Suppliers have access to information pertaining to my organization's procurement process.

With regards to suppliers having access to information pertaining to the organization's procurement process, only $22 \%$ of the respondents expressed that suppliers were able to obtain information about their organization's procurement process. A bigger percentage of it, that is, $88 \%$ were either not sure or in disagreement with the fact. These results give an indication that supplier engagement was low or there was none because suppliers were not given access to the procurement process because they are not seen as part of the Organization. 


\section{Confidential and proprietary information of firms and individuals competing for business is not devulged to the public and competitors.}

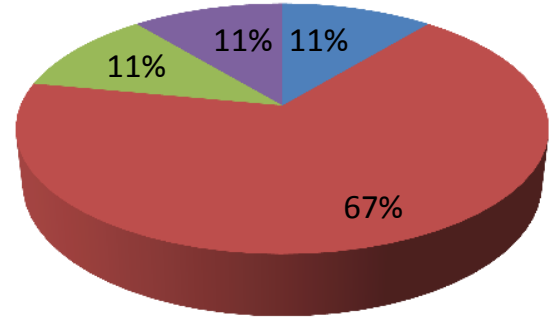

Strongly disagree

Not sure

Strongly agree

Agree

Figure 10: Confidential and proprietary information of suppliers competing for business is not divulged to the public and competitors.

Participant's responses, as seen from above chart, indicates that $78 \%$ of the Procurement staff were either not sure or disagreeing with the fact that in there organizations confidential and proprietary information of firms and individuals competing for business was not being divulged to the public and competitors. Only $22 \%$ agreed. The results shows that there is a great need to practice transparency when conducting the procurement function because organizations in the private are prone to high cases of fraud and misconduct of the procurement personnel through divulging confidential information of suppliers to the public and competitors which compromises professionalism of the staff members.

\subsection{Competition}

\section{I believe the procurement process is manipulated to give preference to some suppliers over others in my organization}

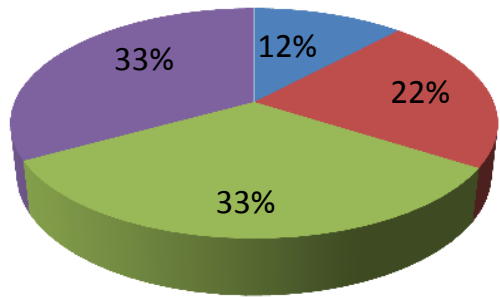

- Strongly disagree

Disagree

Not sure

Agree

Figure 11: I believe the procurement process is manipulated to give preference to some suppliers over others.

With regards to the manipulation of the procurement process to give preference to some suppliers over others $33 \%$ agreed that they believe the procurement process was manipulated to give preference to some suppliers over others. This goes to show that a certain percentage of corruption is there in Procurement in the Private sector. $34 \%$ of the respondents disagreed with the fact which is quite a smaller percentage of organizations which are still not deviating from the laid down procurement procedures. Process audits are strongly recommended under such circumstances to continuously examine if laid down procedures are being followed. This helps avoid the Emergence and growth of corrupt activities in Procurement. 


\section{Generally in my organization, suppliers are given an equal chance to compete for business}

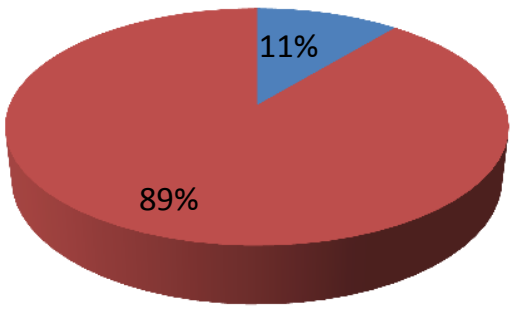

- Strongly agree

Agree

Figure 12: Generally in my organization, suppliers are given an equal chance to compete for business.

Generally enough room to compete for business is given to most suppliers as exhibited by the findings of this study. $89 \%$ of the organizations in the Private sector positively confirmed that they were giving their suppliers an equal chance to compete for business except for a very small portion of $11 \%$ of the organizations which are not giving equal chances of competition to their suppliers. Competition is a crucial element to be allowed to suppliers because it helps in getting high quality goods for less thereby achieving value for money.

\section{The Procurement Unit in my organization has measures in place to manage the scrutiny and confidentiality of documents}

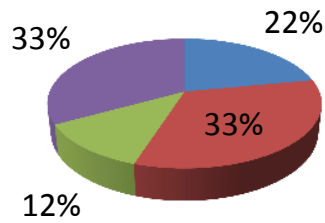

$$
\begin{aligned}
& \text { dsagree } \\
& \text { Not sure } \\
& \text { Strongly agree } \\
& \text { Agree }
\end{aligned}
$$

Figure 13: The Procurement Unit in my organization has measures in place to manage the scrutiny and confidentiality of documents.

It has emerged from the findings that security measures in place to manage scrutiny and confidentiality of documents in Procurement are inadequate as indicated by $45 \%$ of the respondents who were not sure and some disagreed. The Procurement functions deals with strict and confidential information of different suppliers as such there has to be strong and adequate measures in place to control and monitor access to such proprietary information of suppliers and lack of these measures as is happening in Private sector organizations will result in the procurement personnel being tempted to use such information for their personnel advantages thereby compromising probity in procurement. $45 \%$ of the respondents responded positively which ids quite a low response.

\section{Procurement staff in my organization uses information known to them by virtue of their official position, to their advantage.

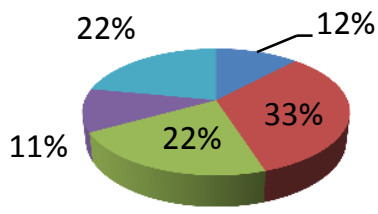 \\ - Strongly disagree \\ Disagree \\ Not sure \\ Strongly agree}

Figure 14: Procurement staff in my organization uses information known to them by virtue of their official position, to their advantage. 
What emerges from form the above results is that $45 \%$ of procurement staff in private sector organizations does not use information known to them by virtue of their official position, to their advantage whilst $22 \%$ were not sure and $33 \%$ agreed. This shows that there is more need to review the ethical codes of conduct in the organizations and continuously carry out probity audits in order constantly remind procurement staff on the need to maintain ethical standards.

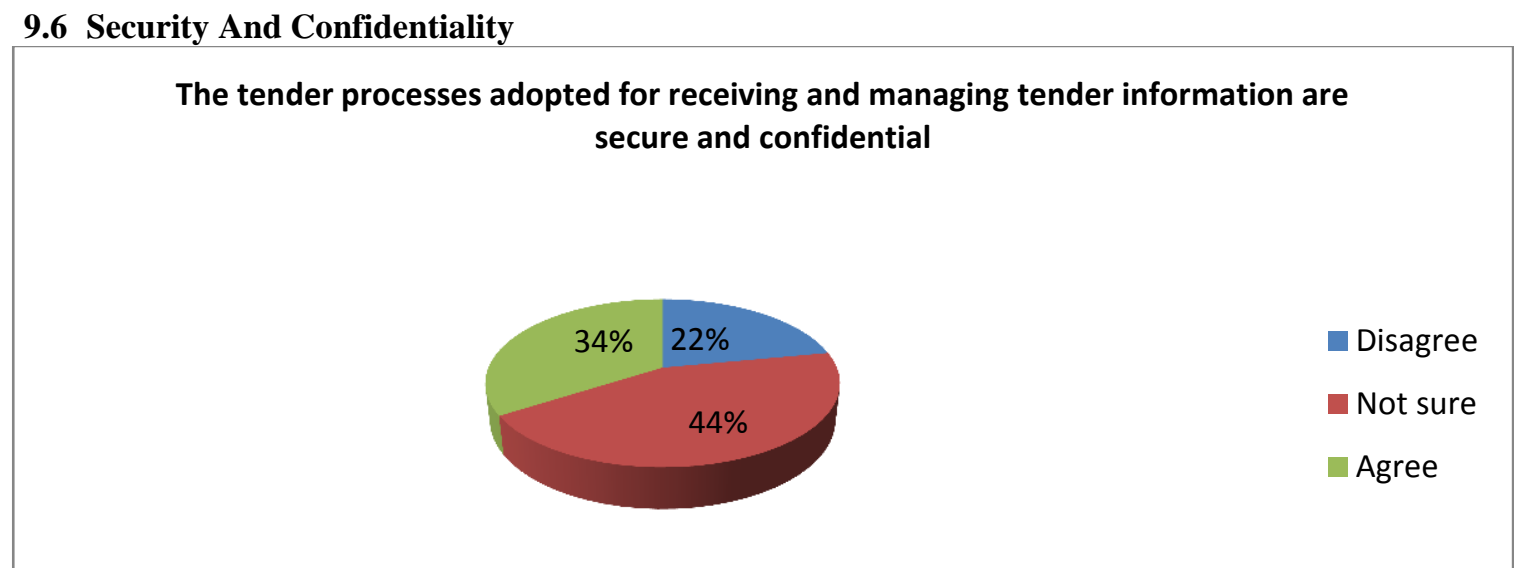

Figure 15 Processes adopted for receiving and managing tender information are secure and confidential.

Security and confidentiality of the processes adopted for receiving and managing tender information have been regarded by many respondents as unsecure and not confidential as shown by $66 \%$ of the respondents which were either not sure or disagreeing. Only $34 \%$ responded positively. There is a strong need to review the security nature of the tender processes adopted because the current result leaves the procurement processes prone to corrupt activities. One of the objectives of this study is to avoid the potential for misconduct, fraud and corruption. Lack of security and confidentiality of processes adopted will expose the procurement staff exposed to the risk of corruption and fraud.

\subsection{Efficiency}

Prices paid for goods and services are resonable and represent good value.

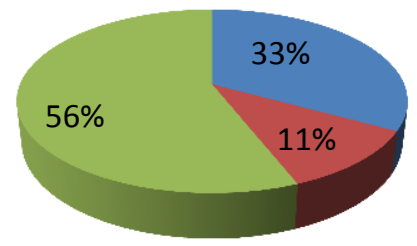

Not sure

- Strongly agree

$\square$ Agree

Figure 16: Prices paid for goods and services are reasonable and represent good value.

Results represent that the organizations are working strongly towards achieving value for money as indicated by $77 \%$ of the responses which positively confirmed that prices paid for goods and services were fair and represented good value. This implies that the goods and services are acquired on the best possible terms and are appropriate to the requirement .However in order to improve on efficiency there is still need to exercise caution on all purchases as indicated by $33 \%$ which are not sure in order to achieve full value for money.

\section{Conclusions}

It is true that procurement is being conducted with probity in mind in the private sector as proved by this study but probity principles were not wholesomely practiced in these organizations. The majority of the organizations have shown that they were observing some principles very well whilst poorly observing some, a situation which hinders full benefits of observing probity in procurement.

Fairness and Competition were positively observed in procurement in the private sector. Majority of the companies in the private sector were giving treating their suppliers fairly and allowing them to compete for business thereby increasing chances of obtaining the best outcome. 
The Procurement personnel in the Private Sector organizations need to have a wider perspective and understanding of the importance and contributions of conducting the procurement function with probity in mind.

There is a high possibility and risk of fraud and misconduct in procurement in the private sector due to relaxed or absence of strict security measures to manage confidentiality of information held by the procurement department.

Procurement processes and procedures are being twisted and deviated from by procurement personnel not wholesomely for the benefit of the organizations but to some extend it is done for personal benefit which is unethical.

\section{Recommendations}

From the findings the researcher recommends that,

1. Probity audits be frequently conducted after a given period of time in order to be sure that laid down procedures, laws and regulations are being followed by the Procurement personnel when undertaking their mandate at the organization.

2 Security measures need to be put in place to manage the scrutiny and confidentiality of documents in the Procurement departments.

3 Training in the form of workshops and seminars with organizations such as the State Procurement Board or other Procurement professionals is required for the Procurement staff to be kept abreast of the best procurement practices.

4 Organizations must develop codes of ethics which guides the Procurement personnel when carrying out their duties and acts as a yardstick with which procurement performance will be measured against it.

5 Procurement staff must be educated on the strategic significance of purchasing and supply management and the potential it holds for gaining a competitive advantage in an increasingly difficult and competitive business environment.

\section{Reference}

[1]. Eyaas and Oluka PN (2011), Explaining non compliance in public compliance in Uganda.

[2]. Gilbert Muponda (2009), Privatisation can aid Zimbabwes economic recovery.

[3]. Gray and Jenkins (1985) Administrative politics in British government

[4]. Guthrie J(2012) Application of Accrual Accounting in the Australian public sector.

[5]. McMillan and Schumacher (1997) Introdution to designing qualitative research.

[6]. Ng C and Ryan C (2001) The practice of probity Audits in one Australian jurisdiction

[7]. Nyasha Chizu, ( Newsday 16.12.2013) Value for money procurement

[8]. Palmier L (2000) Corruption and Probity. Asian journals of political sciences.

[9]. Rahman,R.A, Hui, W.S, Othman,R.O, Normah O and Haron N.H (2011). Procurement issues in Malaysia

[10]. Steve Moro (2011) Probity in procurement policy. SA Health.

[11]. W.M.J.Hugo, J.A Badenhorst-Weiss (2011). Purchasing and Supply Management. 